\title{
Amyloid in normal and pathological parathyroid glands
}

\author{
T. J. ANDERSON ${ }^{1}$ AND S. W. B. EWEN \\ From the Department of Pathology, University of Aberdeen, Aberdeen
}

SYNOPSIS Two groups of parathyroid glands have been examined for intrafollicular amyloid. In glands removed surgically it was found in nine cases $(16 \%)$; in glands removed at necropsy it was found in 23 cases $(46 \%)$. Also, two postmortem cases of systemic amyloidosis showed involvement of parathyroid glands with an entirely different distribution of amyloid. Compared with other amyloids the tinctorial properties of the intrafollicular amyloid were uniform in reactions with Congo red and Thioflavin $T$, but the intensity of the staining reaction for amino acids tryptophan and tyrosine was not constant for the follicle amyloid. This variation may be a feature of a maturation process but the derivation of this amyloid remains uncertain.

Intrafollicular amyloid in the parathyroid glands of hyperparathyroidism was described by Leedham and Pollock (1970). In the course of a review of surgical material from cases of hyperparathyroidism (Anderson, 1974) it was apparent that amyloid could be detected not only in pathological but also in normal tissue. The present study was made to assess the frequency of cases with amyloid in parathyroid glands and to examine its characteristics.

\section{Materials and Methods}

\section{CASE SELECTION}

Parathyroid tissue was examined from 106 cases in two groups. The surgical series comprised 56 cases of clinical hyperparathyroidism. Material consisted of tissue from neck exploration submitted to the Department of Pathology at Aberdeen between 1962 and 1972. The postmortem series of 50 cases was selected from 1972 on the basis of availability of parathyroid tissue. The major causes of death were complications of degenerative vascular disease, carcinomatosis, and bacterial infection. In two additional cases, of rheumatoid arthritis and multiple myelomatosis, in which there was systemic amyloidosis the glands were assessed separately.

TISSUE PROCESSING AND MICROSCOPY All tissue was formalin fixed. Sections at three

'Present address: Department of Pathology, University of Edinburgh, Edinburgh, EH8 9AG

Received for publication 23 May 1974. levels stained by haematoxylin and eosin were screened for intrafollicular amorphous eosinophilic material that developed anomalous colours when viewed between crossed polars (Brewer, 1964). Positive examples were confirmed as amyloid on subsequent Congo red stains (Puchtler, Sweat, and Levine, 1962) by repeat examination under polarized light for dichroism and green birefringence.

The dimethylaminobenzaldehyde nitrite method (Adams, 1957) was used to demonstrate tryptophan and the diazotization-coupling method (Glenner and Lillie, 1959) for tyrosine. Thioflavin $T$ stains were made according to the method of Vassar and Culling (1959) for examination with a Leitz Orthoplan microscope by mercury vapour illumination (HBO 200). In one case paraffin-embedded material was reprocessed for examination by the electron microscope (Zeiss EM 9).

\section{Results}

APPEARANCE AND DISTRIBUTION OF AMYLOID Intrafollicular amyloid was identified in both pathological (fig 1) and normal tissue (fig 2) by its dichroism and green birefringence under polarized conditions after Congo red stain. The deposits often had a laminated structure and showed considerable variation in amount, both as to size and number of positive follicles in a gland. The largest follicles were always in pathological tissue and the greatest amount was present in an adenoma with predominantly follicular architecture. In a few glands, mostly postmortem samples, only a single amyloid 


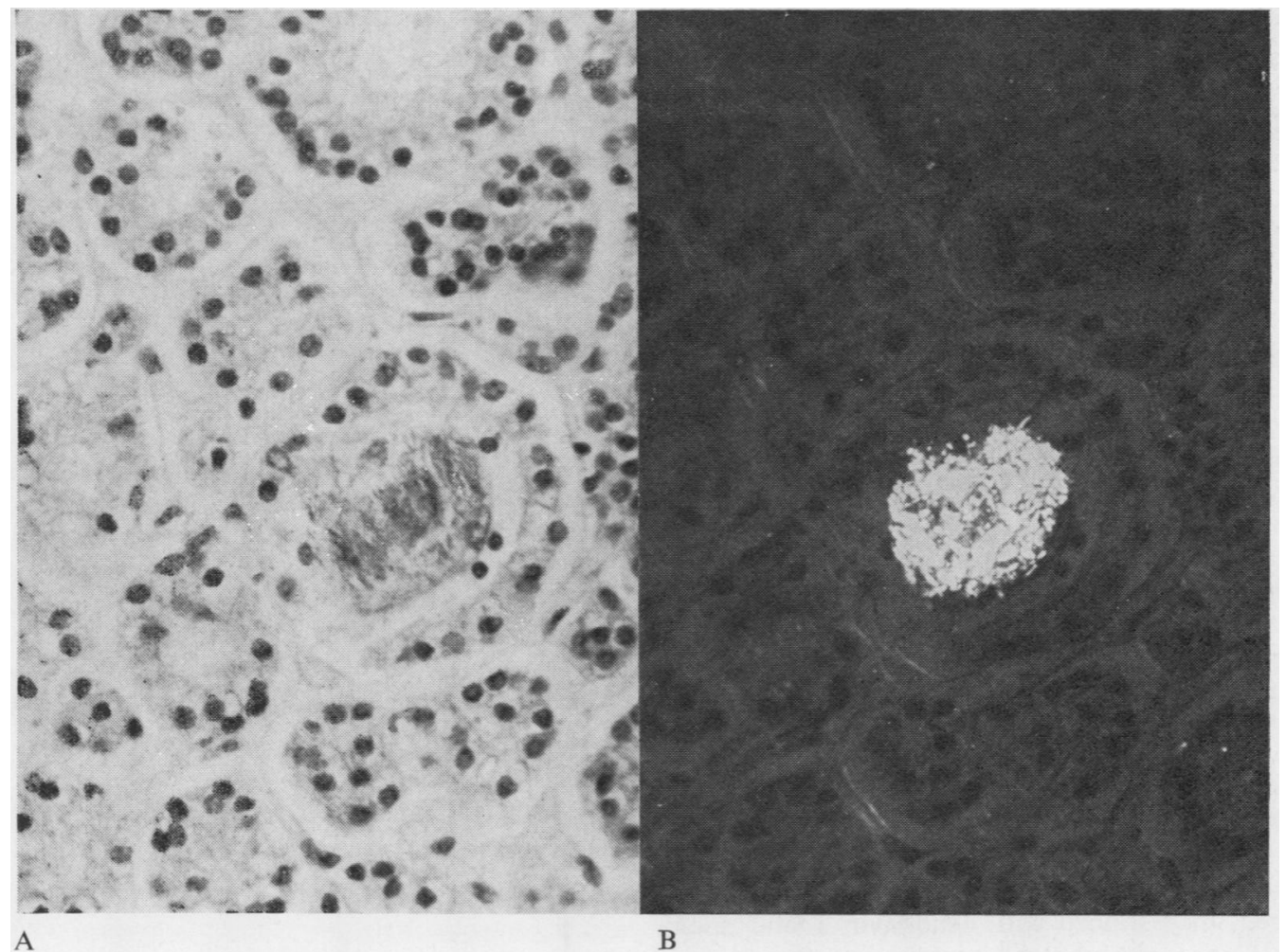

Fig 2 Normal gland with intrafollicular amyloid. The largest follicle (arrow) shows an amyloid centre within colloid. $(A)$ ordinary light, $(B)$ polarized light; Congo red, $\times 400$.

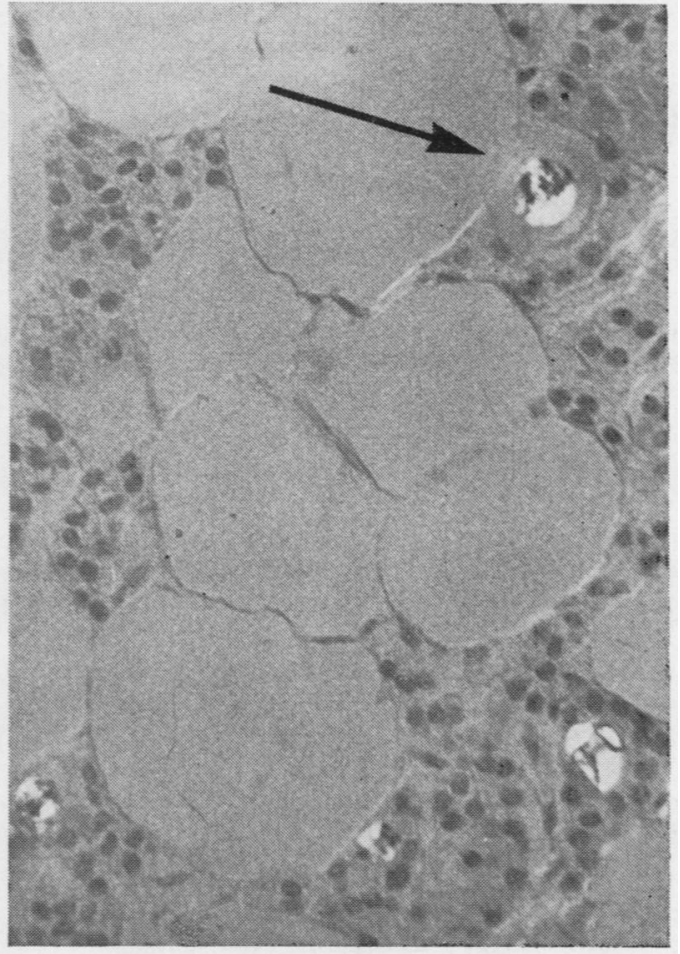

B 
follicle per section was identified. No account of this range was taken in assessment, however, since the aim was to evaluate the total number of affected cases.

Amyloid was detected in situations adjacent to all three parenchymal cells-either chief, water clear, or oxyphil in type. Although no consistent pattern of distribution was observed, affected follicles were most frequent in the gland periphery and in association with colloid-containing follicles. Whereas most of the positive follicles contained amyloid alone, occasional follicles showed an amyloid centre within colloid (fig 2) and others a ring of amyloid around colloid or an empty space. Unidentified cell nuclei were infrequently observed within amyloid follicles. Also microdeposits of amyloid were identified in one surgical case, but these were extracellular in position.

Assessment of Thioflavin $T$ positivity by green fluorescence was complicated by the autofluorescence of follicle colloid, thus obligating the prior identification of putative amyloid on unstained sections. In two cases in which this proved possible the results of sequential studies of follicles first viewed unstained, then stained with Thioflavin $T$ and finally with Congo red, showed concurrence for amyloid with both methods.

Electron microscopy of tissue processed from paraffin-embedded material showed a fibrillary network composed of long, unbranched fibres with a width between 8 and $15 \mathrm{~nm}$. The resolution and detail were impaired by prior processing.

\section{INCIDENCE OF AMYLOID IN PARATHYROID GLANDS}

The number of cases in which intrafollicular amyloid was detected in glands removed surgically and at necropsy is shown in table I. Pathological tissue, both adenoma and hyperplasia, as well as normal glands showed involvement. In the pathological series seven of the nine amyloid cases were in the adenoma category, a frequency somewhat greater than the proportion of cases with that diagnosis in the series (table II). However, it must be emphasized that in two of the seven adenoma cases amyloid was identified only in the accompanying 'normal' glands.

\begin{tabular}{|c|c|c|c|c|c|}
\hline \multicolumn{6}{|l|}{ es } \\
\hline . & $\ldots$ & $\ldots$ & $\ldots$ & .. & .. \\
\hline $\begin{array}{l}\text { Hyperplasia } \\
\text { Uncertain but pathological }{ }^{1}\end{array}$ & $\ldots$ & . & . & . & \\
\hline Uncertain but pathological ${ }^{1}$ & $\ldots$ & .. & . & .. & \\
\hline ogical tissue identified & $\cdots$ & .. & . & * & \\
\hline
\end{tabular}

Table II Histological diagnosis in cases of hyperparathyroidism

'Includes three cases with only one gland.

Differences are evident in the proportion of positive cases between the surgical $(16 \%)$ and postmortem $(46 \%)$ series. Comparison is, however, complicated by the difference in age of the two groups, for the male cases particularly. Arranging postmortem cases with amyloid according to age (fig 3 ) showed an apparent trend of increase with age but the dif ferences were not statistically significant. Neverthe

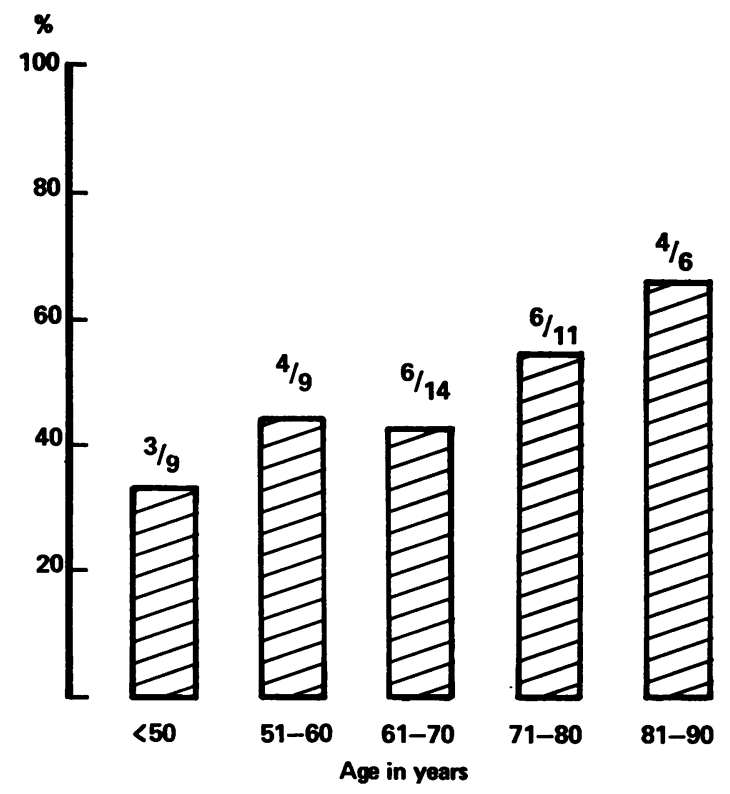

Fig 3 Percentage of postmortem cases showing amyloid arranged by decade.

\begin{tabular}{|c|c|c|c|c|c|c|}
\hline Series & Sex & Cases & Age (mean) & Amyloid & Age (mean) & Diagnosis \\
\hline $\begin{array}{l}\text { Surgical } \\
\text { (56) }\end{array}$ & $\begin{array}{l}\mathbf{M} \\
\mathbf{F}\end{array}$ & $\begin{array}{l}22 \\
34\end{array}$ & $\begin{array}{l}20-68(49 \cdot 1) \\
35-75(58 \cdot 1)\end{array}$ & $\begin{array}{l}1 \\
8\end{array}$ & $\begin{array}{l}57 \\
57-75(59-8)\end{array}$ & $\begin{array}{l}\text { A } \\
6 A, 1 H, 1 N\end{array}$ \\
\hline $\begin{array}{l}\text { Postmortem } \\
\text { (50) }\end{array}$ & $\begin{array}{l}\mathbf{M} \\
\mathbf{F}\end{array}$ & $\begin{array}{l}19 \\
31\end{array}$ & $\begin{array}{r}34-86(66.4) \\
8-90(60.4)\end{array}$ & $\begin{array}{l}11 \\
12\end{array}$ & $\begin{array}{l}40-86(66 \cdot 5) \\
49-90(67 \cdot 7)\end{array}$ & $\begin{array}{l}\mathbf{N} \\
\mathbf{N}\end{array}$ \\
\hline
\end{tabular}

Table I Age range and sex of all surgical and postmortem cases examined together with those showing intrafollicular amyloid

$\mathrm{A}=$ adenoma, $\mathrm{H}=$ hyperplasia, $\mathrm{N}=$ normal 


\begin{tabular}{|c|c|c|c|c|}
\hline \multirow[t]{3}{*}{ Glands Found } & \multicolumn{4}{|l|}{ Series } \\
\hline & \multicolumn{2}{|c|}{ Surgical } & \multicolumn{2}{|c|}{ Postmortem } \\
\hline & Total & Amyloid & Total & Amyloid \\
\hline $\begin{array}{l}1 \\
2 \\
3 \\
4 \\
5\end{array}$ & $\begin{array}{r}3 \\
7 \\
15 \\
27 \\
4\end{array}$ & $\begin{array}{l}0- \\
1(14 \cdot 3 \%) \\
2(13 \cdot 3 \%) \\
6(22 \cdot 0 \%) \\
0-\end{array}$ & $\begin{array}{r}7 \\
13 \\
20 \\
10\end{array}$ & $\begin{array}{r}3(42.8 \%) \\
4(30.7 \%) \\
11(55.0 \%) \\
5(50.0 \%)\end{array}$ \\
\hline
\end{tabular}

Table III Number of cases with intrafollicular amyloid related to the numbers of glands retrieved for examination

less a factor to be considered to affect the number of amyloid cases in either series was the number of glands detected per case. In table JII the cases have been grouped according to the number of glands examined and it is evident that the greatest proportion of amyloid cases occurred where three or four glands were found; yet no case with five glands was positive and a significant proportion of cases with one or two glands showed amyloid.

\begin{tabular}{lll}
\hline Amyloid-positive Glands & \multicolumn{2}{l}{ Number of Cases } \\
\cline { 2 - 3 } & Surgical & Postmortem \\
\hline 1 & 1 & 18 \\
2 & 5 & 3 \\
3 & 3 & 1 \\
4 & 0 & 1 \\
\hline
\end{tabular}

Table IV Cases with intrafollicular amyloid arranged according to number of glands involved

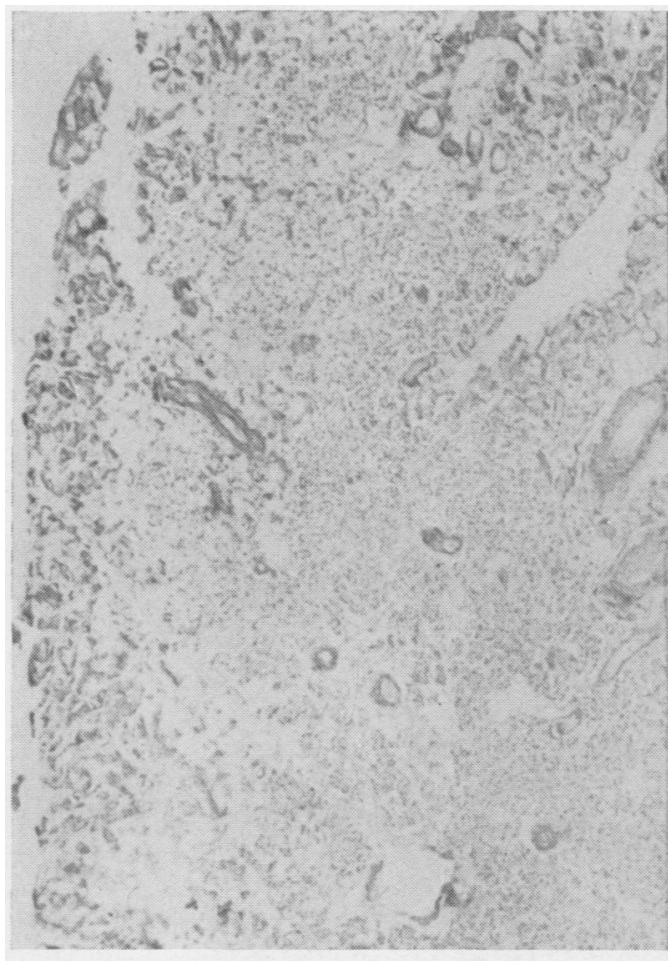

A

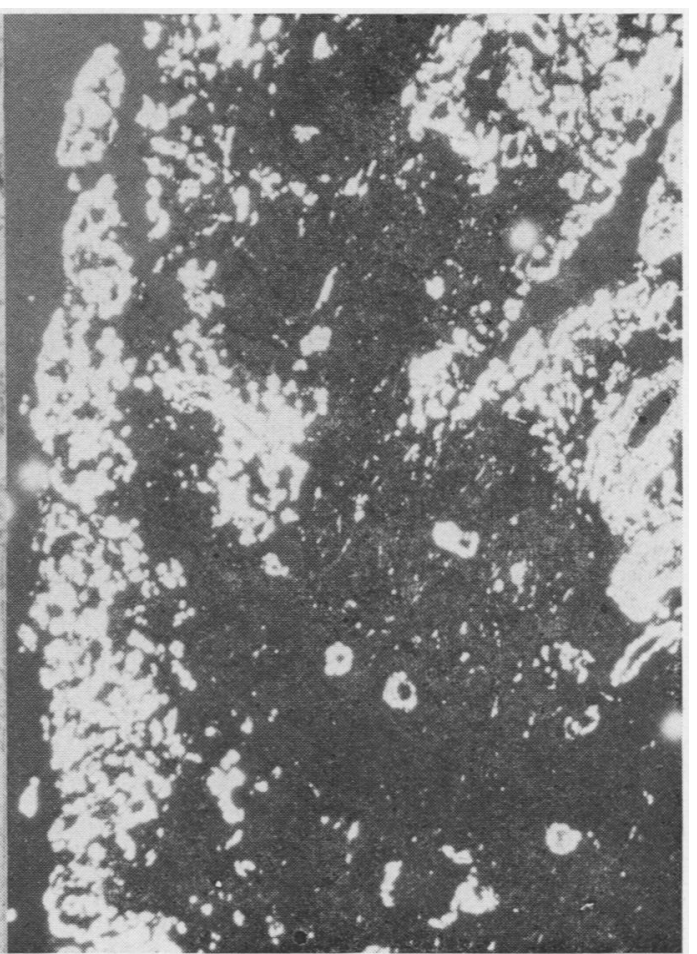

B

Fig 4 Parathyroid gland in systemic amyloidosis showing amyloid distributed periarterially and in the interstitium at the gland periphery. $(A)$ ordinary light, $(B)$ polarized light; Congo red, $\times 40$. 


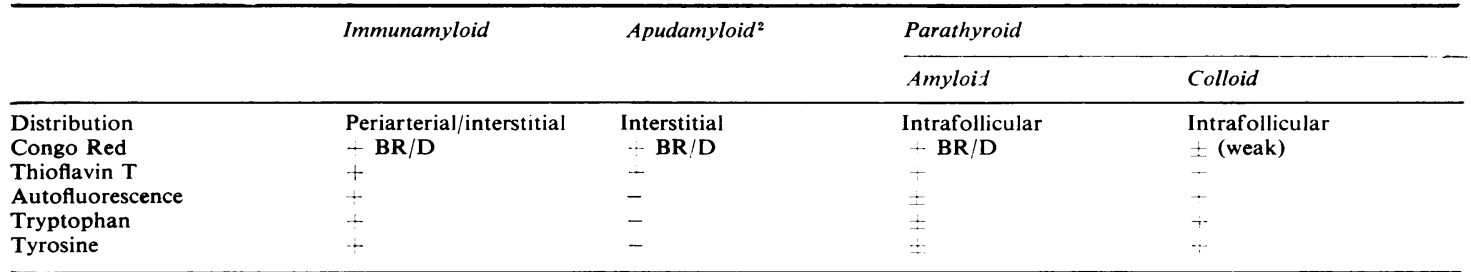

Table V Distribution and staining characteristics of parathyroid intrafollicular amyloid for comparison with other amyloids and follicle colloid ${ }^{1}$

${ }^{1}(+)=$ positive, $( \pm)=$ variable,$(-)=$ negative, $B R / D=$ green birefringence and dichroism ${ }^{2}$ Pearse, Ewen, and Polak, 1972.

Another variable which arose was the number of glands involved per case, although it was realized that the methods used provided only a minimal level of detection. Table IV demonstrates that a high proportion of the surgical cases showed multigland involvement, whereas $75 \%$ of the postmortem cases showed only a single positive gland.
SYSTEMIC AMYLOIDOSIS

The two cases showed a distribution of parathyroid amyloid that was entirely different from the cases already described. In each case all four glands were involved and deposition was prominent periarterially as well as in the interstitium around the periphery of the gland (fig 4).

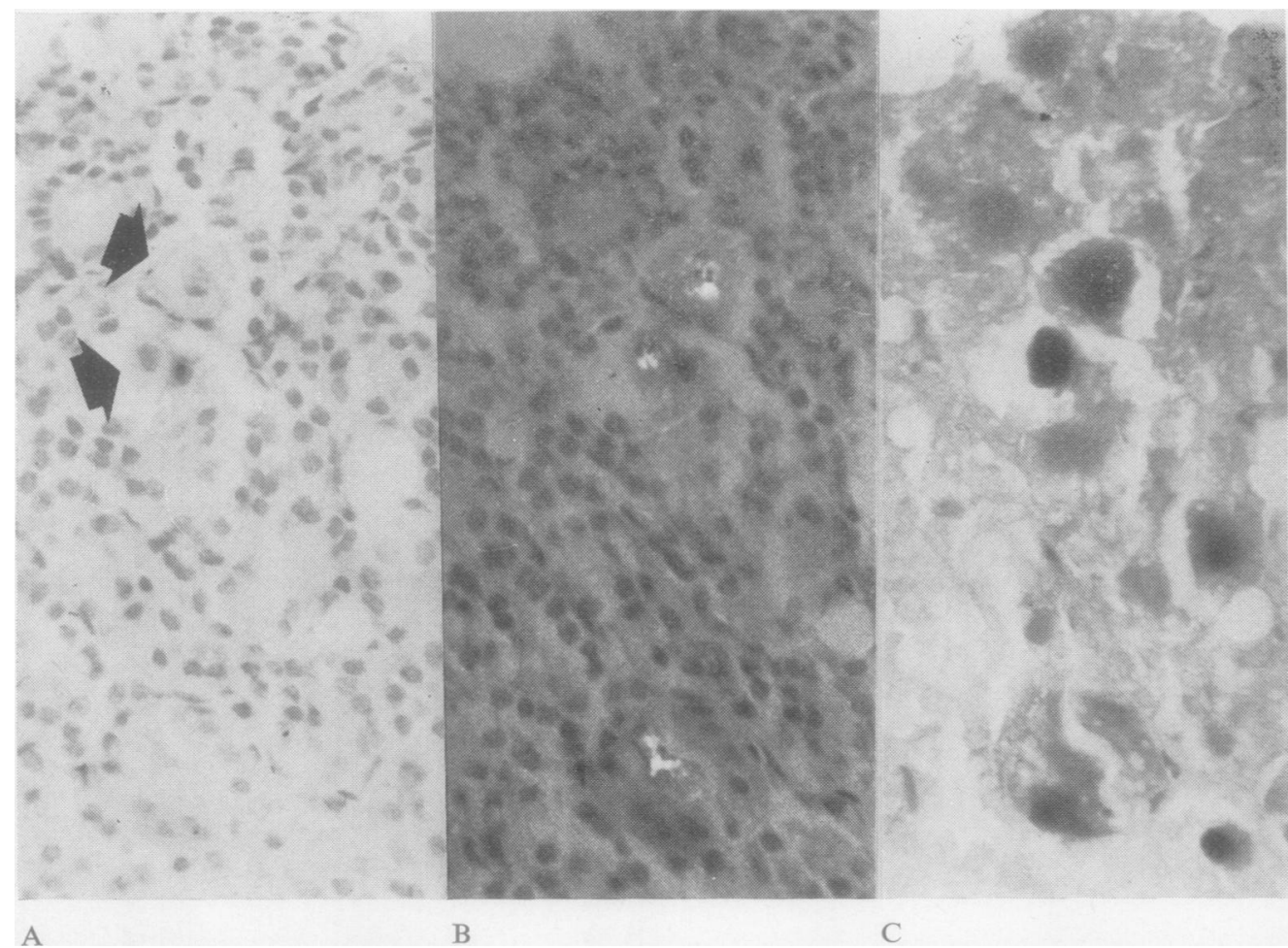

Fig 5 Tryptophan reactivity of intrafollicular amyloid. The same field was photographed under three conditions for positive identification of amyloid. Congo red, $(A)$ ordinary light, $(B)$ polarized light; $(C)$ stained for tryptophan, $\times 400$. 


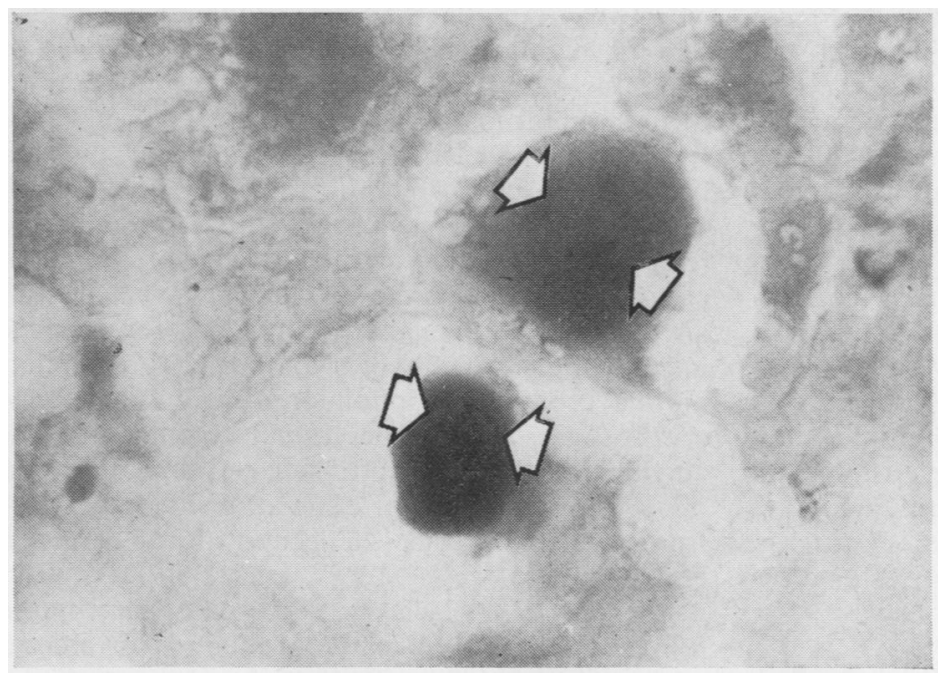

Fig 6 Two large follicles of fig 5 at high magnification (oil) to show altered tryptophan reactivity of amyloid areas (arrows). $\times 1200$.

\section{CHARACTERIZATION OF PARATHYROID}

AMYLOID

The reactions of parathyroid amyloid to a variety of tests is shown in table $\mathrm{V}$ for comparison with amyloids of other types. Microscopic appearances after Congo red or Thioflavin $T$ treatments were the same for all, but the property of autofluorescence was difficult to assess in the parathyroids because of the strong autofluorescence of follicle colloid, thus leading to confusion. Further complication was added by the observation that amyloid follicles, when identified, showed variable autofluorescence. In some it was moderate whereas in a few it was absent.

A similar variability was encountered in the reactions of intrafollicular amyloid for the amino acids tryptophan and tyrosine. The follicle colloid was always strongly positive, whereas areas corresponding to amyloid showed diminished reactivity (figs 5,6 ). The variation in amino acid staining intensity, which existed within a single gland, was examined more closely in a total of 35 follicles in glands from nine cases (two surgical and seven at necropsy), when follicle material was identified on sections stained first with Congo red and subsequently restained for tryptophan. Compared with the strong reaction of the more homogeneous colloid, the amyloid was non-homogeneous in reaction and was of equivalent intensity in five follicles, of only moderate intensity in 29 , and negative in one.

\section{Discussion}

The difference in intrafollicular amyloid of the surgical and the postmortem series is mainly one of degree. Although there is no evidence that this amyloid is of clinical significance two major issues which require comment are its incidence and its derivation.

\section{INCIDENCE}

The proportion of positive cases in the present hyperparathyroid series is comparable with that of Leedham and Pollock (1970), but in the postmortem cases the frequency is much greater than both and is even greater than the $30 \%$ recorded for postmortem cases in Boston (Lieberman and De Lellis, 1973). Two factors which need to be taken into account, however, are the age of patients and the restriction of assessment in surgical cases to biopsies of normal glands. In view of the acknowledged localization of amyloid within glands and the limitation of screening procedures these biopsies cannot be compared equally with the glands completely removed at necropsy. Also, age has been considered to have an influence on the incidence of localized amyloid deposits in the pancreas (Schwartz, 1965) and other endocrine organs (Ravid, Gafni, Sohar, and Missmahl, 1967). Thus, despite lack of clear evidence that intrafollicular amyloid was commoner in parathyroid glands of older age groups at necropsy (fig 3), differences in mean ages between the present postmortem and surgical series, especially for males, may be an additional factor to explain the lower incidence among surgical cases. It is of interest, though, that the mean age of the amyloid-positive males in the London series was 43.2 years (Leedham and Pollock, 1970).

Although amyloid was more evident in postmortem cases there was no impression of any accu- 
mulation in glands with age. This suggests that there is a metabolic turnover of the amyloid which deserves closer examination (Lendrum, Slidders, and Fraser, 1972; see below). Certainly, the frequency with which amyloid is detected in normal glands indicates that it may be associated with physiological function, the excess in pathological tissue being connected with overactivity.

With regard to pathological tissue, the predominance of adenoma cases also contrasts with the experience of Leedham and Pollock (1970), seven of whose nine cases showed chief cell hyperplasia that in five instances was associated with multiple endocrine adenomatosis. The present results suggest that this association is fortuitous, and indeed, a single case of multiple endocrine adenomatosis in the Aberdeen surgical series was negative for amyloid.

DERIVATION OF AMYLOID

Origins of amyloid from light (kappa) immunoglobulin fragments have been proposed (Glenner, Ein, and Terry, 1973) for some forms of systemic amyloidosis. Differences between this type and intrafollicular amyloid were apparent in the present study. Another type of amyloid is associated with endocrine tumours, notably medullary carcinoma of thyroid (Williams, Brown, and Doniach, 1966) and pancreatic islet cell tumours (Porta, Yerry, and Scott, 1962). The cells which give rise to these endocrine tumours in different organs have been assigned to one system, the APUD cell system (Pearse, 1969), and it is currently believed that this amyloid, termed 'apudamyloid', is formed from the C-peptide portion remaining after the metabolism of prohormone to yield the active product (Pearse, Ewen, and Polak, 1972). These authors reported differences in histochemical characteristics between apudamyloid and the amyloid of immunoglobulin origin (immunamyloid), notably the absence of tryptophan and tyrosine from the former.

It is apparent that parathyroid amyloid does not conform wholly to the characteristics of either of these two forms. No significance can yet be attached to the variable reactivity shown by intrafollicular amyloid for these amino acids, which were chosen for this study on an empirical basis. However, Lendrum et al (1972) have drawn attention to an assumed aging process for renal amyloid (immunamyloid) to explain alterations in staining characteristics, a diminution of intensities being equated with older age of maturation. So also might a maturation process underlie the variation in demonstrable tryptophan content of amyloids. At present, it does not seem warranted to distinguish different types of amyloid on the basis of histochemical reactions which may be influenced by an unpredictable process of maturation. Nevertheless the changes in $\overrightarrow{\bar{O}}$ amino acid reactivity provide some explanation for $-\overrightarrow{0}$ the non-uniform autofluorescent appearances. There $\frac{\overline{0}}{}$ is circumstantial evidence (figs 2,6 ) for a connexion $\overline{\bar{p}}$. between amyloid and the follicle colloid, which $\widehat{\varnothing}$ showed consistently strong positive amino acid reactions. Alteration in the composition or confi- ${ }^{\infty}$ guration of the colloid material associated with $\vec{\circ}$ amyloid formation might be responsible for a change $\vec{\overrightarrow{ }}$ in content or reactivity of tryptophan, with an effect $\omega$ on the property of autofluorescence. Pearse et atत्तु (1972) suggested that the autofluorescence of some amyloids is due to tryptophan, tryptophan metab-. olites, or possibly to transfer of the excited state ${ }_{\infty}^{\infty}$ from nearby tyrosine molecules (Kronman and Holmes, 1971).

Rother (1970) believes that some parathyroid $\stackrel{5}{-}$ follicles are involved in the production or storage of hormone, but the nature of the hormone is une certain. Leedham and Pollock (1970) favoured ancक association of amyloid with calcitonin production, $\mathrm{a}-\overrightarrow{\mathrm{O}}$ process for which there is some evidence from human parathyroid gland extracts (Galante, Gudmundsson, Matthews, Tse, Williams, Woodhouse, and Mac-o Intyre, 1968) despite lack of histological evidence for cells of the APUD system in human para-ō thyroid glands. Calcitonin is of course better recog-⿳亠丷厂巾 nized as the product of thyroid parafollicular $\mathrm{C}$ cellso which are part of the APUD system (Pearse, 1969). $\overrightarrow{0}$ Yet parathormone, too, needs to be considered as 3 there is evidence from human tissue that its formation is via a prohormone (Martin, Greenberg, and? Michelangeli, 1973), thus conforming with the pattern of association between endocrine amyloids: and such a mechanism of polypeptide hormone 3 . manufacture. It is worth noting that amyloid has beeno observed in bovine glands (Black, Capen, and Arnaud, 1973) in a situation which corresponds with the immunofluorescent identification of parat-? hormone (Perkin, Bader, Tashjian, and Goldhaber 1968).

It has been deduced that a $\beta$-pleated sheet is theon structural conformation of amyloid fibres (Glenner, $N$ Eanes, and Page, 1972). Although polymerization of the polypeptide hormones, insulin, and glucagon $\omega$ yields material with the physical properties identicak to amyloid (Glenner, Eanes, Termine, Bladen, anc? Linke, 1973) further work will be required to substantiate an inference that the amyloid of the present study is hormone derived.

We acknowledge the technical assistance of $\mathrm{Mr} A \stackrel{\mathrm{Q}}{\mathrm{D}}$ McKinnon and Miss S. Robertson, and also the preparation of illustrations by the Department of Medical Illustration, Aberdeen. 


\section{Referenees}

Adams, C. W. M. (1957). A p-dimethylaminobenzaldehyde-nitrite method for the histochemical demonstration of tryptophan and related compounds. J. clin. Path., 10, 56-62.

Anderson, T. J. (1974). Mast cells in parathyroid glands of hyperparathyroidism. J. clin. Path., 27, 31-34.

Black, H. E., Capen, C. C., and Arnaud, C. D. (1973). Ultrastructure of parathyroid glands and plasma immunoreactive parathyroid hormone in pregnant cows fed normal and high calcium diets. Lab. Invest., 29, 173-185.

Brewer, D. B. (1964). Renal Biopsy, p. 20, Arnold, London.

Galante, L., Gudmundsson, T. V., Matthews, E. W., Tse, A., Williams, E. D., Woodhouse, N. J. Y., and MacIntyre, I. (1968). Thymic and parathyroid origin of calcitonin in man. Lancet, 2, 537-539.

Glenner, G. G., Eanes, E. D., and Page, D. L. (1972). The relation of the properties of Congo-red stained amyloid fibrils to the B conformation. J. Histochem. Cytochem., 20, 821-826.

Glenner, G. G., Eanes, E. D., Termine, J. D., Bladen, H. A., and Linke, R. P. (1973). The structural characteristics of some proteins having the properties of Congo red-stained amyloid fibrils. (Abstr.) J. Histochem. Cytochem., 21, 406.

Glenner, G. G., Ein, D., and Terry, W. D. (1973). The immunoglobuorigin of amyloid. Amer. J. Med., 52, 141-147.

Glenner, G. G., and Lillie, R. D. (1959). Observations on the diazotization-coupling reaction for the histochemical demonstration of tyrosine: metal chelation and formazan variants. J. Histochem., 7, 416-422.

Kronman, M. J., and Holmes, L. G. (1971). The fluorescence of native, denatured and reduced-denatured proteins. Photochem. Photobiol., 14, 113-134.

Leedham, P. W., and Pollock, D. J. (1970). Intrafollicular amyloid in primary hyperparathyroidism. J. clin. Path., 23, 811-817.

Lendrum, A. C., Slidders, W., and Fraser, D. S. (1972). Renal hyalin. A study of amyloidosis and diabetic fibrinous vasculosis with new staining methods. J. clin. Path., 25, 373-396.
Lieberman, A., and DeLellis, R. A. (1973). Intrafollicular amyloid in normal parathyroid glands. Arch. Path., 95, 422-423.

Martin, T. J., Greenberg, P. B., and Michelangeli, V. (1973). Synthesis of human parathyroid hormone by cultured cells; evidence for release of prohormone by some adenomata. Clin. Sci., 44, 1-8.

Perkin, A. B., Bader, H. I., Tashjian, A. H., Jr., and Goldhaber, P. (1968) Immunofluorescent localisation of parathyroid hormone in extracellular spaces of the bovine parathyroid gland. Proc. Soc. exp. Biol. (N.Y.), 128, 218-221.

Pearse, A. G. E. (1969). The cytochemistry and ultrastructure of polypeptide hormone producing cells of the APUD series and the embryologic, physiologic, and pathologic implications of the concept. J. Histochem. Cytochem., 17, 303-313.

Pearse, A. G. E., Ewen, S. W. B., and Polak, J. M. (1972). The genesis of Apudamyloid in endocrine polypeptide tumours: histochemical distinction from Immunamyloid. Virchows Arch. Abt. B. Zellpath., 10, 93-107.

Porta, A. E., Yerry, R., and Scott, R. F. (1962). Amyloidosis of functioning islet cell adenomas of the pancreas. Amer. J. Path., 41, 623-627.

Puchtler, H., Sweat, F., and Levine, M. (1962). On the binding of Congo red by amyloid. J. Histochem. Cytochem., 10, 355-364.

Ravid, M., Gafni, J., Sohar, E., and Missmahl, H. (1967). Incidence and origin of non-systemic microdeposits of amyloid. J. clin. Path., 20, 15-20.

Rother, Von P. (1970). Das Kolloid der Glandulae parathyreoideae. Acta histochem. (Jena.), 35, 135-152.

Schwartz, P. (1965). Senile cerebral, pancreatic insular and cardiac amyloidosis. Trans. N.Y. Acad. Sci., 27, 393-413.

Vassar, P. S., and Culling, C. F. A. (1959). Fluorescent stains, with special reference to amyloid and connective tissues. Arch. Path., 68, 487-498.

Williams, E. D., Brown, C. L., and Doniach, I. (1966). Pathological and clinical findings in a series of 67 cases of medullary carcinoma of the thyroid. J. clin. Path., 19, 103-113. 